\title{
KINERJA PT PLN UNIT INDUK DISTRIBUSI JAKARTA RAYA DENGAN SUPPLY CHAIN OPERATION REFERENCE
}

\author{
Sugeng Santoso ${ }^{1}$, Alfi Nurzaki ${ }^{2}$, Arga Santoso ${ }^{3}$, Chano Benawan ${ }^{4}$, Didin Wahyudin ${ }^{5}$ \\ ${ }^{1}$ Universitas Mercubuana, Jakarta,sugeng.santoso@mercubuana.ac.id \\ ${ }^{2}$ Fakultas Pasca Sarjana Universitas Mercubuana, Jakarta,nurzakialfi4@gmail.com \\ ${ }^{3}$ Fakultas Pasca Sarjana Universitas Mercubuana, Jakarta, argasantoso1993@gmail.com \\ ${ }^{4}$ Fakultas Pasca Sarjana Universitas Mercubuana, Jakarta, chano.foenale@gmail.com \\ ${ }^{5}$ Fakultas Pasca Sarjana Universitas Mercubuana, Jakarta,didin.wahyudin09@yahoo.com

\begin{tabular}{ll|lll}
\hline Article history & \multicolumn{1}{l}{} \\
\hline Dikirim tanggal & $: 13 / 06 / 2020$ & Diterima tanggal & $:$ & $15 / 09 / 2020$ \\
Revisi pertama tanggal & $: 15 / 09 / 2020$ & Tersedia online tanggal & $:$ & $29 / 09 / 2020$ \\
\hline
\end{tabular}

\begin{abstract}
ABSTRAK
PT PLN (Persero) Unit Induk Distribusi Jakarta Raya terus melakukan peningkatan pelayanan kepada pelanggan dengan melakukan pemasangan baru sesuai dengan waktu yang ditargetkan. Kecepatan pemasangan adalah salah satu faktor yang mempengaruhi pelayanan dan persepsi pelanggan terhadap perusahaan. PT PLN (Persero) Unit Induk Distribusi Jakarta Raya melayani penyambungan listrik Tegangan Rendah (TR) dan Tegangan Menengah (TM). Berdasarkan identifikasi yang dilakukan ditemukan adanya kendala yang dialami perusahaan sehingga menyebabkan pekerjaan penyambungan menjadi lama. Hal ini ditemukan pada layanan Tegangan Menengah pola 100 hari yang dibutuhkan diatas target 100 hari. Lamanya proses pelayanan mengalami kendala dari sisi eksternal maupun internal perusahaan. Oleh karena itu, perlu adanya analisa mendalam dengan metode tertentu agar perusahaan dapat mencapai target yang telah ditetapkan ditahun berikutnya. Penelitian ini meneliti atribut reliability dan responsivness menggunakan metrik Perfect Order Fullfilment (POF) dan Order Fulfilment Cycle Time (OFCT). Hasil penelitian didapatkan bahwa faktor perizinan dan ketidaksiapan pelanggan menjadi alasan utama keterlambatan pemasangan listrik Tegangan Menengah pola 100 hari.
\end{abstract}

Kata Kunci: PT PLN (Persero) Unit Induk Distribusi Jakarta Raya, SCOR, Layanan

\section{ABSTRACT}

PT PLN (Persero) Jakarta Raya Main Distribution Unit continuously improves services to customers by conducting new installations following the targeted time. Installation speed is one of the factors that influence the function and customer perception of the company. PT PLN (Persero) Jakarta Raya Distribution Main Unit serves the connection of Low Voltage (TR) and Medium Voltage (TM) electricity. Based on the identification carried out, it was found that there were obstacles experienced by the company, causing the connection work to belong. This is located in the Medium Voltage service pattern of 100 days required above the 100-day target. The length of the service process is experiencing problems from the external and internal sides of the company. Therefore, there needs to be an in-depth analysis of certain methods to achieve the targets set the following year. This study examines the attributes of reliability and responsiveness using the Perfect Order Fulfillment (POF) and Order Fulfilment Cycle Time (OFCT) metrics. The results showed that the licensing factor and customer unpreparedness were the main reasons for the delay in installing the 100-day Medium Voltage electricity pattern.

Keywords: PT PLN (Persero) Jakarta Raya Main Distribution Unit, SCOR, Services 


\section{PENDAHULUAN}

PT. PLN (Persero) merupakan Badan Usaha Milik Negara yang bergerak dibidang kelistrikan. Didirikan pada tanggal 1 Januari 1965, PT. PLN (Persero) memiliki tujuan untuk menyelenggarakan usaha penyediaan tenaga listrik bagi kepentingan umum dalam jumlah dan mutu yang memadai serta memupuk keuntungan dan melaksanakan penugasan pemerintah dibidang ketenagalistrikan. Sebagai perusahaan utama yang bergerak dalam memproduksi dan mendistribusikan listrik kepada masyarakat umum, PT PLN (Persero) mempunyai inti kegiatan bisnis menjalankan usaha penyediaan tenaga listrik yang mencakup pembangkitan tenaga listrik, penyaluran tenaga listrik (transmisi), distribusi tenaga listrik, perencanaan dan pembangunan sarana penyediaan tenaga listrik, pengembangan penyediaan tenaga listrik, dan penjualan tenaga listrik.

Dalam rantai pasok PT PLN, kegiatan distribusi tenaga listrik adalah tahap akhir dalam pengiriman tenaga listrik, yaitu merupakan proses membawa listrik dari sistem transmisi listrik menuju ke konsumen listrik. Oleh karena itu unit distribusi berkontak langsung dengan konsumen akhir sehingga keberhasilan unit distribusi mempengaruhi pelayanan pelanggan PT PLN secara keseluruhan.

Salah satu unit distribusi besar adalah Unit Induk Distribusi Jakarta Raya (Disjaya) yang dipercaya untuk menyalurkan listrik di wilayah Daerah Khusus Ibukota Jakarta, dimana didalamnya terdapat tempat-tempat strategis atau sering disebut Ring 1 seperti Kawasan Istana, Gedung MPR-DPR, Gedung Gedung pemerintahan, dan Rumah Sakit Nasional. PT PLN Disjaya, juga sebagai unit penyumbang pendapatan terbesar untuk PT PLN (Persero) total pendapatan sekitar 30\%, sehingga naik atau turunnya pendapatan Unit Induk Disjaya akan sangat berpengaruh terhadap pendapatan PT PLN (Persero) secara nasional, dan akan berpengaruh terhadap belanja modal investasi pembangunan pembangkit. Unit Disjaya melayani penyambungan listrik Tegangan Rendah (TR) dan Tegangan Menengah (TM).

Secara keseluruhan rata-rata hari pemasangan baru listrik dari tahun 2016 sampai dengan tahun 2018 berada dibawah dari batas target yang ditentukan oleh PT PLN Disjaya. Tetapi pada saat melakukan penyambungan baru maupun penambahan daya untuk Tegangan Menengah pola 100 hari, ditemukan adanya kendala yang dialami perusahaan sehingga menyebabkan pekerjaan penyambungan menjadi lama sehingga durasi pemasangan yang dibutuhkan diatas target 100 hari. Berikut adalah data Pelanggan Tegangan Menengah pola 100 hari yang melebihi target,

Tabel 1. Pemasangan Tegangan Menengah 100 hari Melebihi Target

\begin{tabular}{|c|l|c|c|}
\hline $\begin{array}{c}\text { Jenis } \\
\text { Transaksi }\end{array}$ & \multicolumn{1}{|c|}{ Nama Pelanggan } & $\begin{array}{c}\text { Durasi } \\
\text { (hari) }\end{array}$ & Kendala \\
\hline PD & YAYASAN AL HAKIM & 316 & Proses bangun gardu oleh pelanggan \\
\hline PB & PT LIEBRO SEJAHTERA & 165 & Proses bangun gardu oleh pelanggan \\
\hline PB & PT KAI TANAH ABANG & 140 & Proses bangunan sipil \\
\hline PD & $\begin{array}{l}\text { PT MULTI ARTHA } \\
\text { PRATAMA }\end{array}$ & 136 & Proses bangunan sipil \\
\hline PD & $\begin{array}{l}\text { PT FORTUNE BELLA } \\
\text { RELAIS }\end{array}$ & 128 & Proses bangun gardu \\
\hline PD & SUSYLIA SUKANA & 120 & Proses bangun gardu oleh pelanggan \\
\hline PB & PT KURNADI ABADI & 115 & Proses bangun gardu oleh pelanggan \\
\hline PB & PERUM HI & 114 & Proses ijin PU \\
\hline PD & PT CAHAYA BUKIT BIRU & 111 & Bangun gardu integrated oleh pelanggan \\
\hline
\end{tabular}




\begin{tabular}{|c|l|c|c|}
\hline $\begin{array}{c}\text { Jenis } \\
\text { Transaksi }\end{array}$ & \multicolumn{1}{|c|}{ Nama Pelanggan } & $\begin{array}{c}\text { Durasi } \\
\text { (hari) }\end{array}$ & Kendala \\
\hline & & & dan ijin SKTIM \\
\hline PB & $\begin{array}{l}\text { PT SUTIOSO } \\
\text { BERSAUDARA }\end{array}$ & 109 & $\begin{array}{c}\text { Bangun gardu integrated oleh pelanggan } \\
\text { dan ijin SKTIM }\end{array}$ \\
\hline
\end{tabular}

Sumber: Data diolah, 2020.

Oleh karena itu, perlu adanya analisa mendalam dengan metode tertentu agar perusahaan dapat mencapai target yang telah ditetapkan. Metode analisa yang akan digunakan adalah model Supply Chain Operations Reference (SCOR) dengan menganalisa atribut reliability dan responsiveness yang merupakan atribut penting bagi sudut pandang konsumen atau pelanggan (customer-facing) dalam lingkup pelayanan pemasangan baru dan penambahan daya listrik pelanggan.

Dalam melakukan penelitian ini penulis ingin menganalisa penyebab keterlambatan dalam penyambungan listrik TM pola 100 hari pada PT PLN UI Disjaya dan Meningkatkan kinerja pelayanan pelanggan dalam penyambungan listrik TM pola 100 hari pada PT PLN UI Disjaya

\section{TINJAUAN LITERATUR}

Supply Chain Management (SCM) adalah suatu metode atau pendekatan untuk mengelola aliran produk, informasi, dan uang secara terintegrasi yang melibatkan pihak-pihak, mulai dari hulu ke hilir yang terdiri dari supplier, pabrik, pelaku kegiatan distribusi maupun jasa-jasa logistik (Pujawan dan Mahendrawati, 2017). Penerapan konsep SCM dalam perusahaan akan memberikan manfaat yaitu kepuasan pelanggan, meningkatkan pendapatan, menurunnya biaya, pemanfaatan asset yang semakin tinggi, peningkatan laba, dan perusahaan semakin besar. Untuk menciptakan koordinasi dan kerjasama antara pihak-pihak dalam supply chain diperlukan adanya suatu sistem pengukuran yang mampu mengevaluasi kinerja supply chain secara tepat. Salah satu pendekatan pengukuran kinerja supply chain adalah dengan metode SCOR (Supply Chain Operation Reference).

Model SCOR adalah suatu model yang dikembangkan oleh Supply Chain Council (SCC). Model SCOR digunakan untuk mengukur dan meningkatkan kinerja total rantai pasokan perusahaan. Model ini meliputi penilaian terhadap pengiriman dan kinerja pemenuhan permintaan, pengaturan inventaris dan aset, fleksibilitas produksi, jaminan, biaya-biaya proses, serta faktor-faktor lain yang mempengaruhi penilaian kinerja keseluruhan pada sebuah rantai pasokan (SCC, 2012).

Model SCOR menyediakan metodologi, diagnostik, dan alat pembandingan yang membantu organisasi membuat peningkatan dramatis dan cepat dalam proses rantai pasokan. SCOR model diorganisasikan dalam lima proses utama rantai pasok yaitu plan, source, make, deliver dan return. Beberapa perusahaan telah membuktikan bahwa SCOR model sudah teruji baik dalam rangka mengukur tingkat kinerja rantai pasok pada suatu perusahaan yang dapat dijadikan sebagai bahan acuan untuk perbaikan proses bisnis selanjutnya (Rizki, et al 2012).

1. Plan (Perencanaan): menggambarkan kegiatan yang terkait dengan pengembangan rencana untuk mengoperasikan rantai pasokan. Proses Plan mencakup pengumpulan persyaratan, pengumpulan informasi tentang sumber daya yang tersedia, menyeimbangkan persyaratan dan sumber daya untuk menentukan kemampuan yang 
direncanakan dan kesenjangan dalam permintaan atau sumber daya dan mengidentifikasi tindakan untuk memperbaiki kesenjangan ini.

2. Source (Sumber): menggambarkan pemesanan atau penjadwalan pengiriman dan penerimaan barang dan jasa. Proses Source mewujudkan penerbitan pesanan pembelian atau pengiriman penjadwalan, penerimaan, validasi dan penyimpanan barang dan penerimaan faktur dari pemasok. Dengan pengecualian untuk Sourcing Engineer-to-Order barang atau jasa, semua proses identifikasi, kualifikasi dan negosiasi kontrak pemasok tidak dijelaskan menggunakan proses ini.

3. Make (Membuat): menggambarkan kegiatan yang terkait dengan konversi bahan atau pembuatan konten untuk layanan. Perakitan, Pemrosesan bahan kimia, Pemeliharaan, Perbaikan, Perbaikan, Daur Ulang, Perbaikan, Pembuatan Ulang termasuk dalam proses ini.

4. Deliver (Mengirimkan): menggambarkan kegiatan yang terkait dengan penciptaan, pemeliharaan, dan pemenuhan pesanan pelanggan. Proses Pengiriman mewujudkan penerimaan, validasi dan pembuatan pesanan pelanggan, penjadwalan pengiriman pesanan, pengambilan, pengemasan dan pengiriman dan penagihan pelanggan.

5. Return (Pengembalian): menggambarkan kegiatan yang terkait dengan arus balik barang. Proses Pengembalian mewujudkan identifikasi kebutuhan untuk kembali, pengambilan keputusan disposisi, penjadwalan pengembalian dan pengiriman dan penerimaan barang yang dikembalikan. Proses perbaikan, daur ulang, perbaikan, dan pembuatan ulang tidak dijelaskan dengan menggunakan elemen Proses pengembalian.

Dengan menggambarkan rantai pasokan menggunakan proses membangun blok ini, model bisa digunakan untuk menggambarkan rantai pasokan yang sangat sederhana atau sangat kompleks menggunakan seperangkat hampir semua rantai pasokan (Chotimah, et al 2012). Model ini telah berhasil menggambarkan dan memberikan dasar untuk peningkatan rantai pasokan untuk proyek-proyek global serta proyek-proyek spesifik lokasi. SCOR menggabungkan elemen-elemen dari rekayasa proses bisnis, metrik, benchmarking, praktik kerja unggulan, dan keterampilan karyawan ke dalam satu kerangka kerja tunggal.

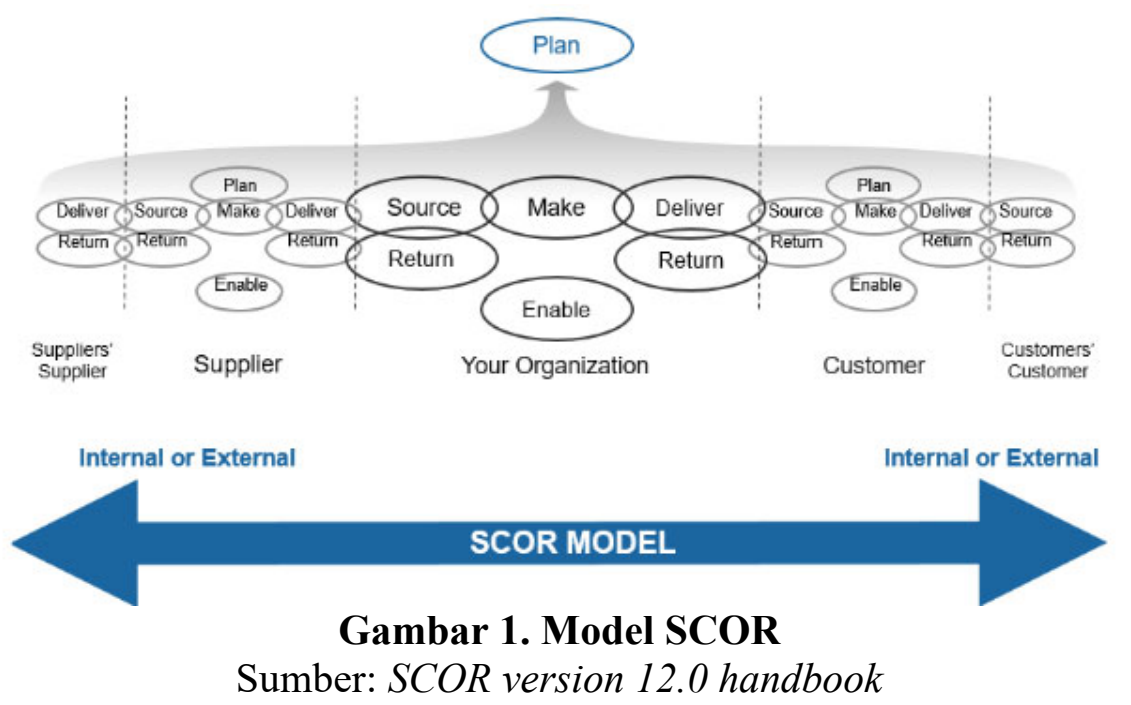

Model SCOR (Amran, et al 2018) mencakup tiga tingkat detail proses yaitu,

1. Metrik level-1 adalah diagnostik untuk kesehatan keseluruhan rantai pasokan. Metrik ini juga dikenal sebagai metrik strategis dan indikator kinerja utama (KPI). Metrik 
level-1 pembandingan membantu menetapkan target realistis untuk mendukung arahan strategis.

2. Metrik level-2 berfungsi sebagai diagnostik untuk metrik level-1. Hubungan diagnostik membantu mengidentifikasi akar penyebab atau penyebab kesenjangan kinerja untuk metrik level-1.

3. Metrik level-3 berfungsi sebagai diagnostik untuk metrik level-2.

Analisis kinerja metrik dari level-1 hingga 3 disebut sebagai dekomposisi metrik, diagnosis kinerja, atau analisis akar penyebab metrik. Dekomposisi metrik adalah langkah pertama dalam mengidentifikasi proses yang perlu diselidiki lebih lanjut. (Proses dihubungkan dengan metrik level-1, level-2 dan level-3).

Tabel 2. Metric Scor Level 1

\begin{tabular}{|l|l|l|}
\hline \multicolumn{1}{|c|}{ Atribut } & \multicolumn{2}{c|}{ Metrik Level-1 } \\
\hline Reliability (Keandalan) & RL.1.1 & Perfect Order Fulfillment \\
\hline Responsiveness (Responsif) & RS.1.1 & Order Fulfillment Cycle Time \\
\hline Agility (Kelincahan) & AG.1.1 & Upside Supply Chain Adaptability \\
\hline & AG.1.2 & Downside Supply Chain Adaptability \\
\hline & AG.1.3 & Overall Value-at-Risk (VaR) \\
\hline Costs (Biaya) & CO.1.1 & Total SC Management Cost \\
\hline & CO.1.2 & Cost of Goods Sold (COGS) \\
\hline \multirow{2}{*}{$\begin{array}{l}\text { Asset Management Efficiency } \\
\text { (Efisiensi Manajemen Aset) }\end{array}$} & AM.1.1 & Cash to Cash Cycle Time \\
\cline { 2 - 3 } & AM.1.2 & Return on Fixed Assets \\
\cline { 2 - 3 } & AM.1.3 & Return on Working Capital \\
\hline
\end{tabular}

Supply Chain Reliability adalah merupakan kemampuan perusahaan dalam melakukan melakukan tugas kegiatan rantai pasoknya seperti yang diharapkan dimana kegiatan tersebut dikatakan tepat dalam waktu, kuantitas dan kualitasnya. Atribut ini berkaitan dengan keandalan suatu proses rantai pasok dari suatu perusahaan. Indikator yang mengukur keandalan proses tersebut adalah Perfect Order Fulfillment (POF) yaitu persentase pesanan yang memenuhi kinerja pengiriman dengan dokumentasi yang lengkap dan akurat dan tidak ada kerusakan pengiriman. Komponen mencakup semua item dan jumlah tepat waktu menggunakan definisi tepat waktu pelanggan dapat ditentukan dengan rumus:

$P O F=\frac{\text { Total Pesanan }- \text { Jumlah Pesanan Bermasalah }}{\text { Total Pesanan }} \times 100 \%$

Supply Chain Responsiveness adalah kecepatan dimana tugas dilakukan. Kecepatan rantai pasokan menyediakan produk kepada pelanggan. Contohnya termasuk metrik siklus waktu. berkaitan dengan kecepatan waktu dalam merespon setiap perubahanperubahan yang terjadi pada suatu proses rantai pasok dari suatu perusahaan. Indikator yang mengukur kecepatan waktu dalam merespon setiap perubahan tersebut adalah Order Fulfillment Cycle Time (OFCT) yaitu jumlah hari yang dibutuhkan sejak dari pesanan diterima sampai produk diterima oleh pelanggan. Besarnya nilai OFCT dapat diukur dari rataan jumlah hari yang dibutuhkan dalam proses penyambungan listrik ke pelanggan, mulai dari pelanggan membayar biaya pemasangan hingga listrik tersambung.

OFCT $=\frac{\text { Jumlah Waktu Penyelesaian Pesanan Berhasil }}{\text { Total Pesanan Berhasil }}$ 


\section{METODE PENELITIAN}

Penelitian ini diawali dengan tahap identifikasi, dimana tahap dilakukan dengan melakukan observasi secara langsung pada PT PLN Disjaya sejak tahun 2015-2017. Dari permasalahan yang telah diidentifikasi selanjutnya dirumuskanlah masalah dan menetapkan tujuan penelitian. Kemudian dilakukan studi pustaka untuk menentukan alat bantu dan referensi penelitian agar penelitian berjalan baik dan benar. Tahap ketiga yang dilakukan yaitu pengumpulan data, yang terdiri dari pengumpulan data primer dengan observasi lapangan dan data sekunder dari internal perusahaan.

Klasifikasi pemetaan didapatkan dengan cara observasi rantai kemudian klasifikasi ini digunakan untuk mengidentifikasi metrik sebagai penyesuaian untuk membuat model hierarki SCOR menggunakan POF dan OFCT karena yang menjadi fokus adalah pelayanan pelanggan dalam bentuk pengukuran tingkat kinerja percepatan pemasangan. Selanjutnya didiagnostik lebih lanjut terkait elemen yang menjadi kendala sehingga mendapatkan akar masalah. Berikut adalah Kerangka Penelitian yang digunakan (Gambar 2).

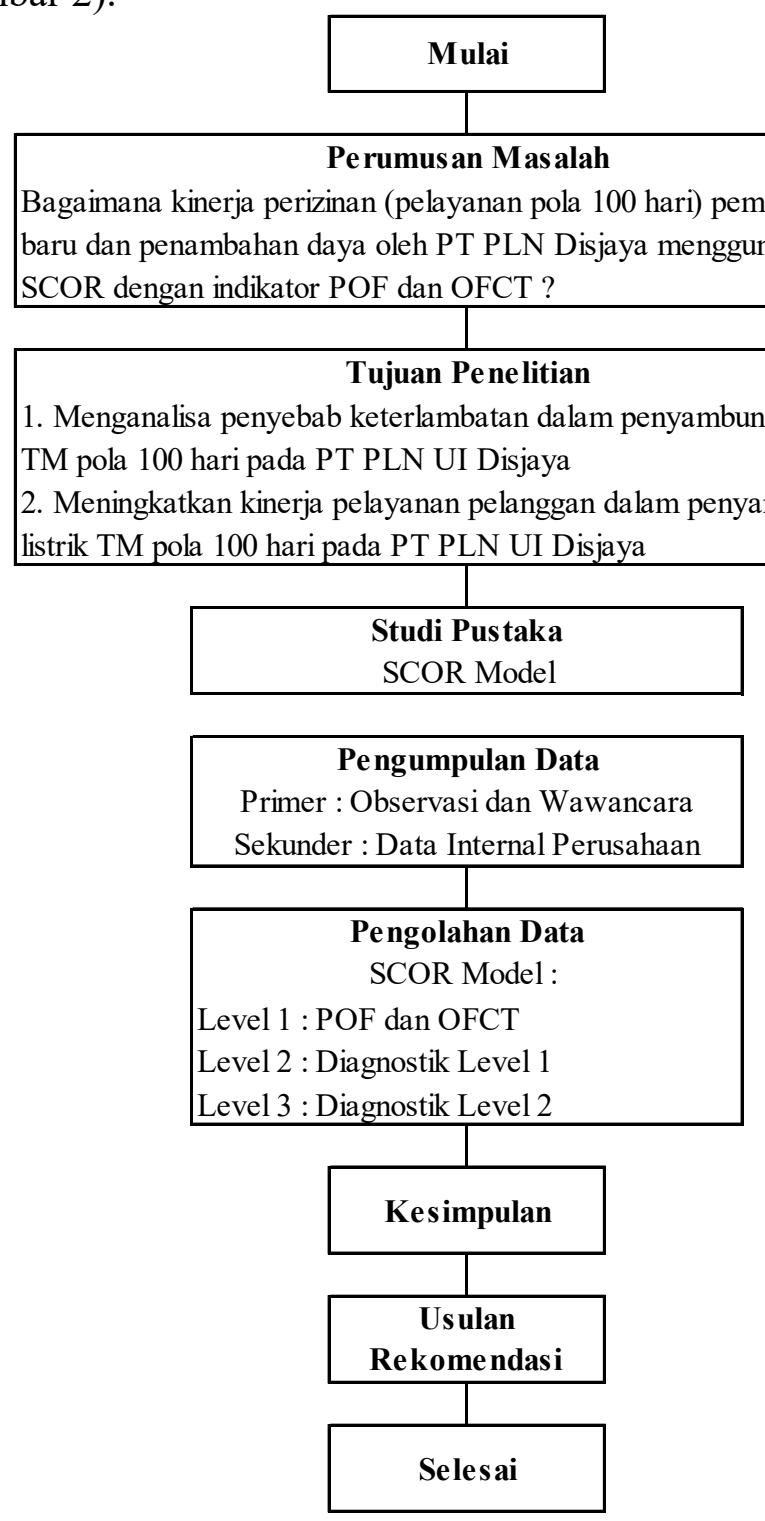

Gambar 2. Kerangka Penelitian 


\section{HASIL PENELITIAN DAN PEMBAHASAN}

\section{Proses Bisnis PT PLN UI Disjaya}

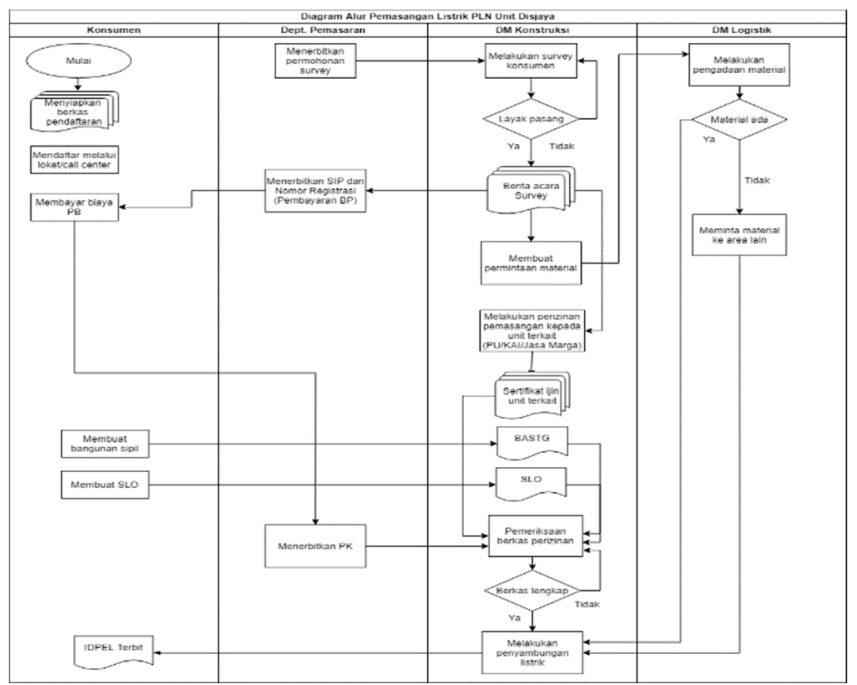

Gambar 3. Proses Penyambungan Listrik PT PLN UI Disjaya

Pada diagram diatas dapat dilihat proses bisnis dari PT PLN UI Disjaya. Terlihat proses kegiatan banyak terjadi pada bagian konstruksi dimana kegiatan survey dan melakukan perizinan terjadi dan dikerjakan di bagian ini.

\section{Analisa SCOR Level 1}

Analisa yang dilakukan pada level 1 ini dimulai dengan mendefinisikan tujuan bisnis perusahaan. Tujuan bisnis PT PLN UID Disjaya adalah memberikan tingkat layanan terbaik kepada semua pelanggan. Untuk mencapai tujuan yang telah ditetapkan maka PT PLN UID Disjaya menetapkan indikator yaitu memberikan tingkat layanan terbaik kepada semua pelanggan dengan waktu pemasangan yang singkat digunakan indikator reliability dan responsiveness to customer demand. Untuk atribut reliability metrik yang digunakan untuk mengukurnya adalah Perfect Order Fulfillment (POF) dan untuk responsiveness metrik yang digunakan untuk mengukurnya adalah Order Fulfillment Cycle Time (OFCT). Setelah tujuan bisnis perusahaan sudah didefinisikan maka langkah selanjutnya adalah melakukan pengukuran terhadap metrik-metrik tersebut dengan hasil pengukurannya dapat dilihat pada perhitungan berikut ini.

\section{Perfect Order Fulfillment (POF)}

Nilai POF dapat dihitung dengan menggunakan data pelanggan yang mendaftar untuk pemasangan baru dan jumlah pelanggan yang tidak terpasang dari tahun 2015 sampai dengan 2017 dengan perhitungan sebagai berikut:

Tabel 3. Perhitungan POF

\begin{tabular}{|c|c|c|c|}
\hline Tahun & $\begin{array}{c}\text { Total } \\
\text { mendaftar }\end{array}$ & $\begin{array}{c}\text { Tidak } \\
\text { terpasang }\end{array}$ & POF \\
\hline 2015 & 190.769 & 4.024 & $97,93 \%$ \\
\hline 2016 & 184.353 & 8.421 & $95,63 \%$ \\
\hline 2017 & 200.383 & 2.022 & $99.00 \%$ \\
\hline
\end{tabular}

Sumber: Data diolah, 2020 
Pada tabel 3, data pada kolom total mendaftar adalah jumlah keseluruhan pelanggan yang mendaftar pada satu tahun, sedangkan untuk kolom tidak terpasang adalah jumlah pelanggan yang masuk daftar tunggu dan melebihi waktu pemasangan listrik. Rata-rata nilai POF PT PLN UID Disjaya adalah 97,93\%+95,63\%+99,00/3 = 97,52\%.

Berdasarkan perhitungan diatas terlihat bahwa dengan nilai POF rata-rata 97,52\%. Kinerja PT PLN UID Disjaya dalam kemampuan memenuhi kebutuhan pelanggan sudah memuaskan namun belum mencapai target yang diharapkan yaitu $100 \%$. Indikator yang menandakan bahwa kemampuan memenuhi pesanan pelanggan suatu perusahaan dalam pengiriman barang adalah nilai POF yang besar. Semakin besar nilai POF yang dimiliki suatu perusahaan maka semakin baik kemampuan perusahaan dalam memenuhi kebutuhan pelanggan. Dengan demikian sebesar mungkin dihilangkan atau diminimalisir jumlah pendaftar yang tidak terpasang.

\section{Order Fulfillment Cycle Time (OFCT)}

Besarnya nilai OFCT dapat dihitung dengan rata-rata hari yang diperlukan untuk melakukan pemasangan listrik pelanggan baru dan penambahan daya TM pola 100 hari.

Tabel 4. Perhitungan OFCT

\begin{tabular}{|c|l|l|}
\hline Tahun & \multicolumn{1}{|c|}{ OFCT } \\
\hline 2015 & & 28,41 \\
\hline 2016 & & 23,44 \\
\hline 2017 & & 30,83 \\
\hline
\end{tabular}

Sumber: Data diolah, 2020

Rata-rata nilai OFCT adalah 28,41+23,44+30,83 $=27,56$ Hari dibulatkan menjadi 28 Hari. Berdasarkan data tersebut dapat disimpulkan bahwa kinerja PT PLN UID Disjaya dalam memenuhi kebutuhan pelanggan sudah baik dan dapat memenuhi harapan pelanggan. Indikator yang menandakan bahwa kemampuan perusahaan untuk memenuhi pesanan pelanggan dengan waktu yang secepat mungkin adalah nilai OFCT yang sekecil mungkin. Semakin kecil nilai OFCT yang dimiliki maka semakin baik kemampuan perusahaan dalam memenuhi pesanan pelanggan dengan waktu yang sekecil mungkin (Sutawijaya, 2016).

\section{Analisa SCOR Level 2}

Pada pemetaan level dua ini akan ditampilkan gambaran dari proses-proses implementasi dari supply chain PT PLN UI Disjaya, mulai dari proses pemasaran, perencanaan, produksi dan distribusi. Selain untuk memperlihatkan aliran material dan informasi, pemetaan ini juga nantinya dapat digunakan untuk menganalisis aktivitas yang tidak terhubung dengan baik. Setelah melakukan pemetaan level dua, tahap selanjutnya adalah menentukan pada proses mana yang menyebabkan POF belum tercapai secara maksimal sebesar 100\%. Untuk OFCT telah sesuai dengan target yang ditentukan oleh PT PLN UI Disjaya. 


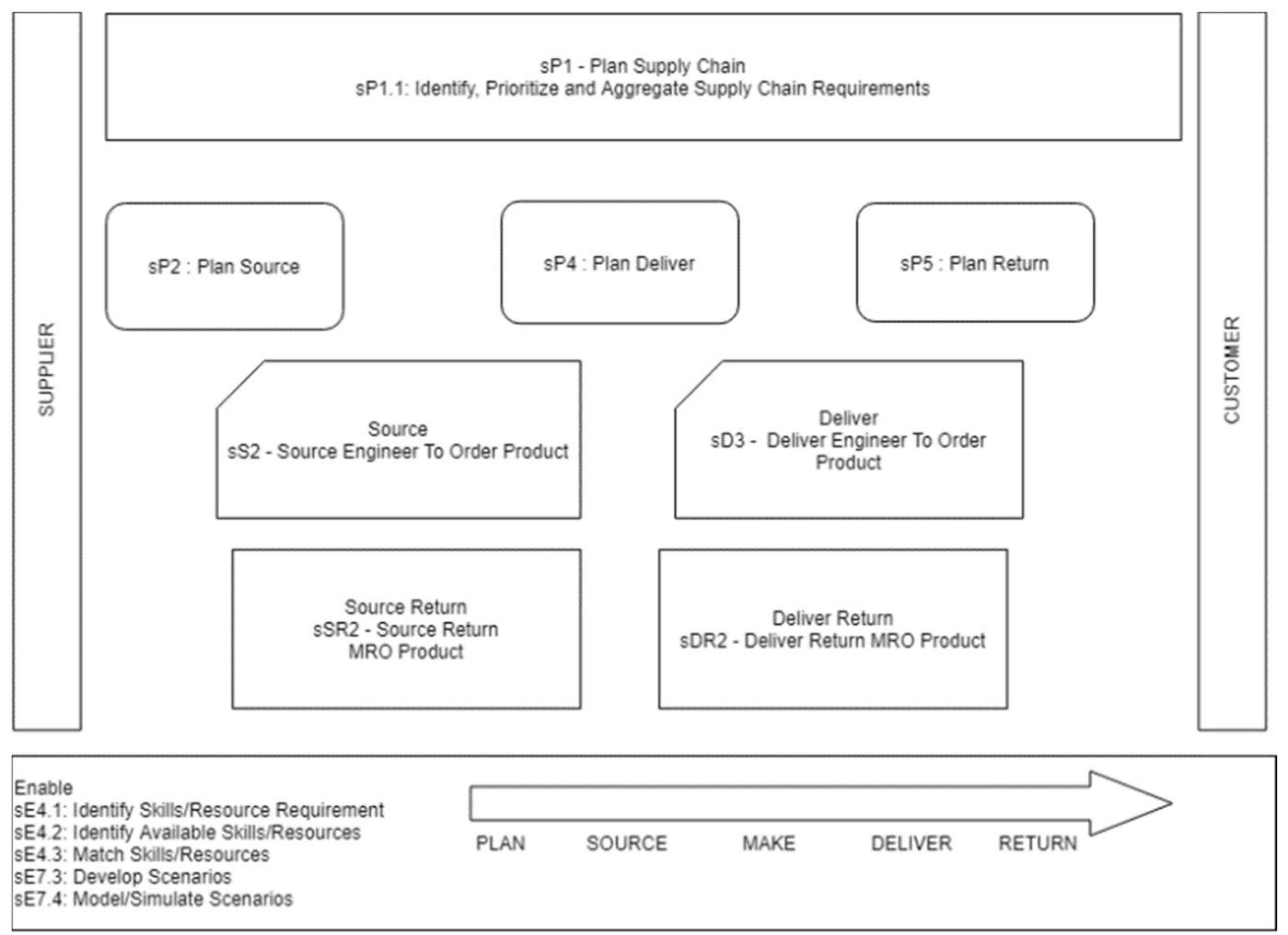

Gambar 4. Analisa Level 2 PT PLN UI Disjaya

Berdasarkan analisa dan wawancara dapat diketahui permasalahan yang ada dibagian deliver berkaitan dengan penyambungan listrik ke pelanggan.

\section{Analisa SCOR Level 3}

Analisis level 3 dilakukan untuk melihat lebih rinci proses deliver, karena dari hasil analisa diperoleh nilai metrik POF yang belum mencapai target. Adapun elemen yang dimaksud dalam proses delivery dapat dilihat pada gambar berikut ini :

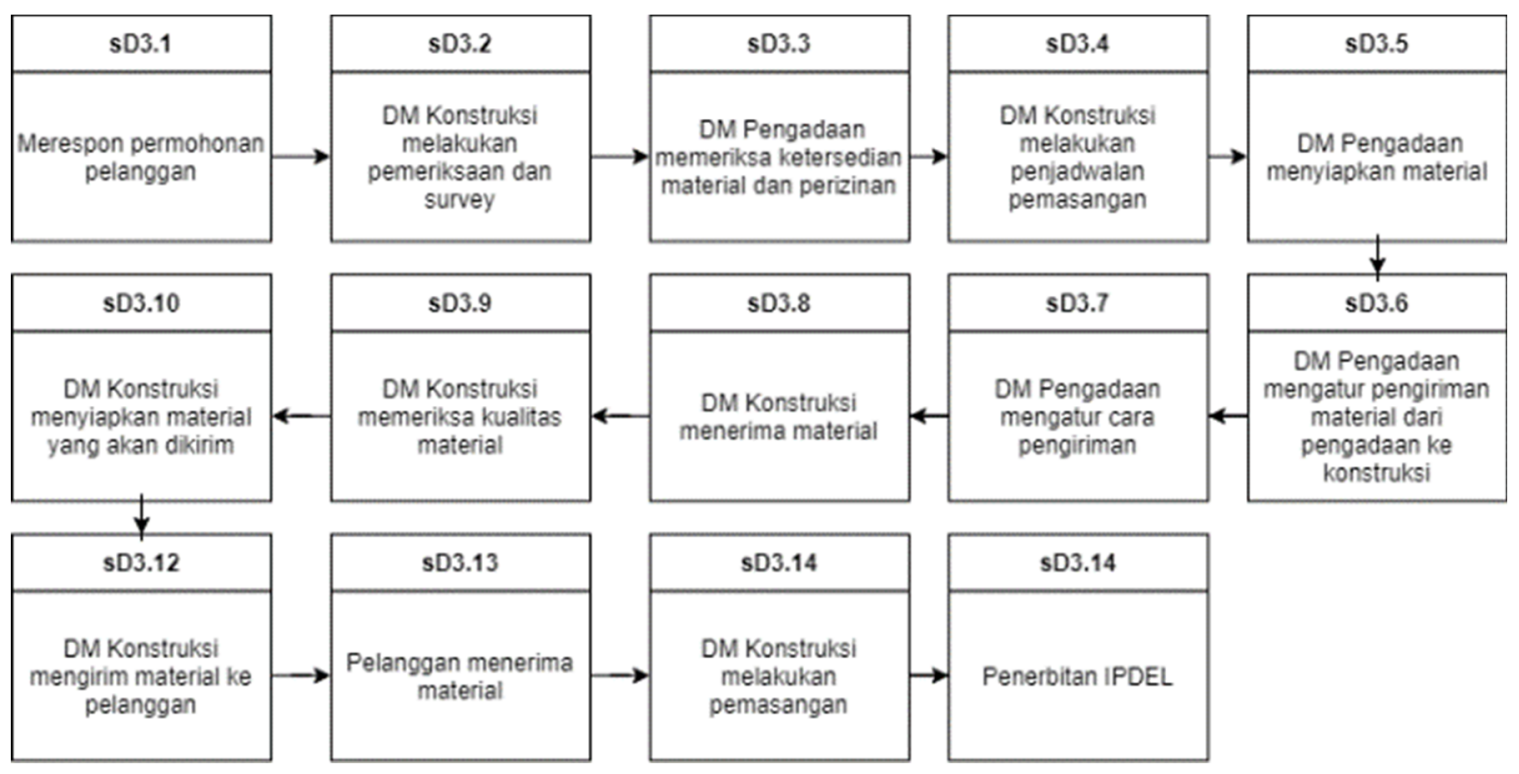

Gambar 5. Analisa Level 3 PT PLN UI Disjaya 
Berdasarkan hasil observasi dan wawancara diperoleh informasi bahwa yang menjadi masalah adalah bagian sD3.2 dan sD3.3 yaitu terkait dengan survey pelanggan dan perizinan. Kemudian bagian tersebut akan dianalisa lebih lanjut dengan diagram fish bone.

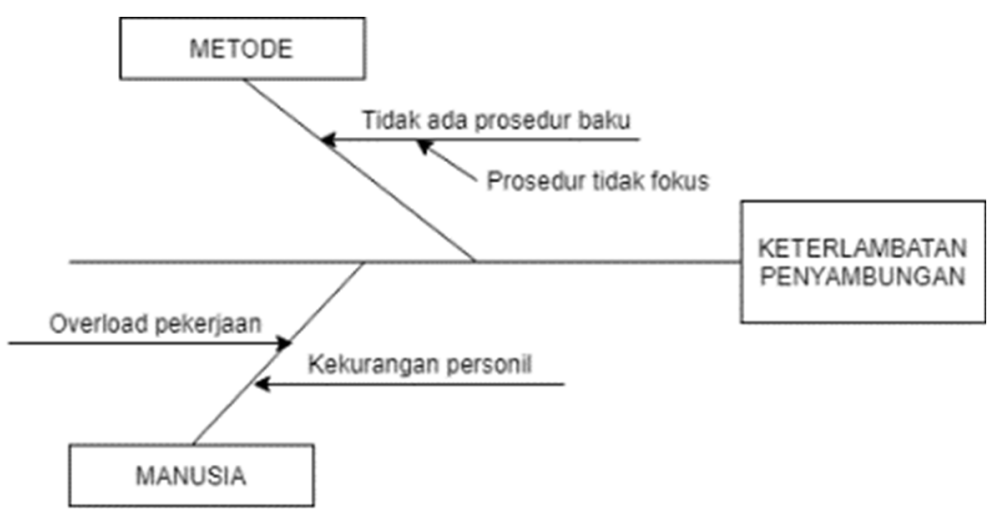

Gambar 6. Diagram Fishbone proses sD3.2

Berdasarkan analisa fishbone diatas dapat dilihat bahwa akar masalah terjadi pada faktor manusia dan metode. Pada faktor metode dilihat bahwa dalam proses perizinan belum ada proses baku yang efektif. Pada faktor manusia, masalah yang terjadi adalah kekurangan pekerja dalam melakukan proses perizinan. Selain itu beban kerja yang dijalani karyawan pada bagian Konstruksi sangat banyak sehingga dalam melakukan proses perizinan pekerja tidak menjadi fokus.

\section{KESIMPULAN DAN IMPLIKASI}

\section{Kesimpulan}

Berdasarkan analisis yang telah dilakukan, maka dapat ditarik kesimpulan yaitu setelah dilakukan dengan analisa SCOR dengan indikator POV dan OCFT diketahui penyebab keterlambatan dalam penyambungan listrik TM pola 100 hari dikarenakan 2 faktor, yaitu dari sisi Eksternal dan Internal. Sisi Eksternal dimana dari sisi ketidaksiapan pelanggan menyediakan instalasi pada bangunan, struktur bangunan yang belum siap dan belum ada SLO. Sisi internal dimana proses perizinan yang belum memiliki proses baku yang efektif dan SDM yang minim sehingga membutuhkan waktu yang lebih lama. Pada tahun 2018 dilakukan perubahan struktur organisasi oleh PT PLN UI Disjaya dimana semua kegiatan perizinan dilaksanakan oleh Deputy Manager Perizinan sehingga kegiatan perizinan bisa menjadi fokus dan terarah. Sehingga pada tahun 2019 durasi pemasangan yang melebihi batas waktu 100 hari sudah sangat berkurang. Pada akhir tahun 2019 tercatat hanya ada 1 pelanggan yang durasi pemasangan melebihi target pemasangan 100 hari. Pada tahun 2018 terjadi peningkatan rata-rata pemasangan yang menjadi lebih cepat yaitu menjadi 19,50 hari yang pada tahun sebelumnya rata-rata lama pemasangan 30,83 hari. 


\section{Kesimpulan}

Saran dari penelitian ini adalah agar PT PLN UI Disjaya dapat lebih memperhatikan faktor eksternal dalam hal ini kesiapan pelanggan dan faktor internal perusahaan yaitu pada proses survey pelanggan. Proses survey pelanggan yang dilakukan oleh perusahaan akan mempengaruhi seberapa jauh kesiapan pelanggan dalam persiapan penyambungan listrik sehingga saat akan dilakukan instalasi listrik, pelanggan sudah siap dan tidak menyebabkan keterlambatan.

\section{REFERENSI}

Amran, T.G., dan Gonawan, V. (2018). Perancangan dan Pengukuran Kinerja Rantai Pasok Produk Alat Kesehatan dengan Supply Chain Operations Rerenrence (Scor). Jurnal Teknik Industri, 8(3), 188-200.

Apics. (2017). SCOR: Supply Chain Reference Model Version 12. The Association for Operations Management (APICS).

Apriyanti, D., Nnurmalina, R., dan Burhanuddin. 2018. Evaluasi Kinerja Rantai Pasok Sayuran Organik dengan Pendekatan Supply Chain Operation Reference (SCOR). Jurnal Ilmiah Manajemen, 8(2), 312-335.

Chotimah, R.R., Purwanggono, B., dan Susanty, A. (2012). Pengukuran Kinerja Rantai PasokMenggunakan Metode SCOR dan AHP Pada Unit Pengantongan Pupuk Urea PT. Dwimatama Multikarsa Semarang. Departemen Teknik Industri, Fakultas Teknik, Universitas Diponegoro.

Kusrini, E., Caneca, V.I., Helia, V.N., dan Miranda, S. (2019). Supply Chain Performance Measurement Usng Supply Chain Operation Reference (SCOR) 12.0 Model: A Case Study in A Leather SME in Indonesia. IOP Conf. Series: Materials Science and Engineering, 697, 1-10.

Pujawan, I.N., dan Mahendrawati. (2017). Supply Chain Management, 3rd. Yogyakarta: ANDI.

Purnomo, Agus. (2015). Analisis Kinerja Rantai Pasok Menggunakan Metode Supply Chain Operation Reference (SCOR) di Industri Tekstil dan Produk Tekstil Sektor Industri Hilir (Studi kasus pada perusahaan garmen PT Alas Indah Remaja Bogor). Prosiding Seminar Nasional Rekayasa Teknologi Industri dan Informasi (ReTII), 10, 739-746.

Rizki, D.A. dan Sitorus, P.M.T. (2012). Analisis Proses Supply Chain Management dengan Metode SCOR Model di PT Bukit Asam Tbk. Tugas Akhir Program Studi S1 Manajemen (Manajemen Bisnis Telekomunikasi \& Informatika) Telkom University.

Sutawija, A.H. dan Marlapa, E. (2016). Supply Chain Management: Analisis dan Penerapan Menggunakan Reference (SCOR) di PT Indoturbine. Jurnal Ilmiah Manajemen, 6(1), 121-138. 
SCC. (2012). Supply Chain Operation Reference Model Version 11. Pittsburgh, PA: Suppy Chain Council Inc.

Wahyuniardi, R., Syarwani, M., \& Anggani, R. (2017). Pengukuran Kinerja Supply Chain Dengan Pendekatan Supply Chain Operation References (SCOR). Jurnal Ilmiah Teknik Industri, 16(2), 123-132. 